\title{
Study of the Behavior of Titanium Alloys as the Cathode for Photovoltaic Hydrogen Production
}

\author{
Chien-Lung Huang, ${ }^{1}$ Yu-Jia Gao, ${ }^{1}$ Tao-Liang Chuang, ${ }^{1}$ Vincent K. S. Hsiao, ${ }^{2}$ and Tair-I Wu ${ }^{3}$ \\ ${ }^{1}$ Metal Industries Research and Development Centre, Kaohsiung, Taiwan \\ ${ }^{2}$ Department of Applied Materials and Optoelectronic Engineering, National Chi Nan University, Puli, Nantou, Taiwan \\ ${ }^{3}$ Department of Materials Engineering, Tatung University, Taipei 10451, Taiwan
}

Correspondence should be addressed to Tair-I Wu; tairiwu@yahoo.com.tw

Received 18 September 2013; Accepted 29 September 2013

Academic Editor: Teen-Hang Meen

Copyright (C) 2013 Chien-Lung Huang et al. This is an open access article distributed under the Creative Commons Attribution License, which permits unrestricted use, distribution, and reproduction in any medium, provided the original work is properly cited.

$\mathrm{CP}-\mathrm{Ti}$ and $\mathrm{Ti}-153$ were adopted in this study to observe their electrochemical behavior in serving as the cathode for photovoltaic hydrogen production. The designed cyclic hydrogenation-solution heat treating processes were performed to increase the hydrogen uptake for both alloys. The results are as follows. (1) Both arsenic trioxide and thiourea showed hydrogenation promotive effect on CP-Ti, while thiourea was an inhibitor for Ti-153 under the applied conditions. (2) Arsenic trioxide showed hydrogenation promotive effect on both Ti-153 and CP-Ti in this study. (3) Ti-153 demonstrated superiority to CP-Ti when serves as the cathode for photovoltaic hydrogen production. The hydrogen mass payload for Ti-153 is 68 times larger than that for CP-Ti.

\section{Introduction}

The available renewable energy on the earth's surface includes the solar power, the wind power, and the hydroelectric power which uses the fall of the river, tidal power, or ocean current power. The wind power and hydroelectric power are, however, significantly limited by the location on the earth, the terrain, or the climate. The solar energy has less restriction in contrast to the abovementioned power sources [1-5]. The applications of sunlight can be divided into two parts: solar thermal energy and photovoltaic (PV). The application of the former is to transform solar energy to obtain heat which could be used in air condition, offer the hot water, or run a heat engine to make electricity [6-8]. PV energy systems employ solar panels in directly converting the sunlight into electricity $[9,10]$.

Since the solar power and the wind power are intermittent energy which means it is interruptible and cannot be a stable source due to the variation of the illuminance of sunlight and the change of wind field, for the commercial feasibility considerations, people have to store the energy when they can give. Unlike other forms of energy, electricity must be utilized when it is being generated or converted immediately into another form of energy. The PV energy system is usually equipped with an electrolyzer and a hydrogen storage tank (see Figure 1) $[1,2,11,12]$. Although the gaseous hydrogen is convenient to store, transport, and apply, the inherent low volume payload rate and high flammability are the death wounds $[13,14]$. It is safer to store hydrogen in solid state, but the increase of hydrogen mass payload rate is still technological challenge [15].

Electrolysis of aqueous sulfuric acid results in hydrogen at cathode surface. The resulted hydrogen can be driven into the cathode as solid solutes or hydrides by adequately adding hydrogenation promoters and selecting cathode material [1620]. Ti-15V-3Al-3Cr-3Sn alloy (Ti-153), as a commonly used $\beta$-Ti alloy, was chosen in this study to compare with commercial purity titanium (CP-Ti) to see the influences of the chemical additives and cathode material on the electrolytic hydrogen uptake.

\section{Materials and Methods}

The cathode materials in sheet form were received at rolled and process annealed state. The specimens were sheared from 


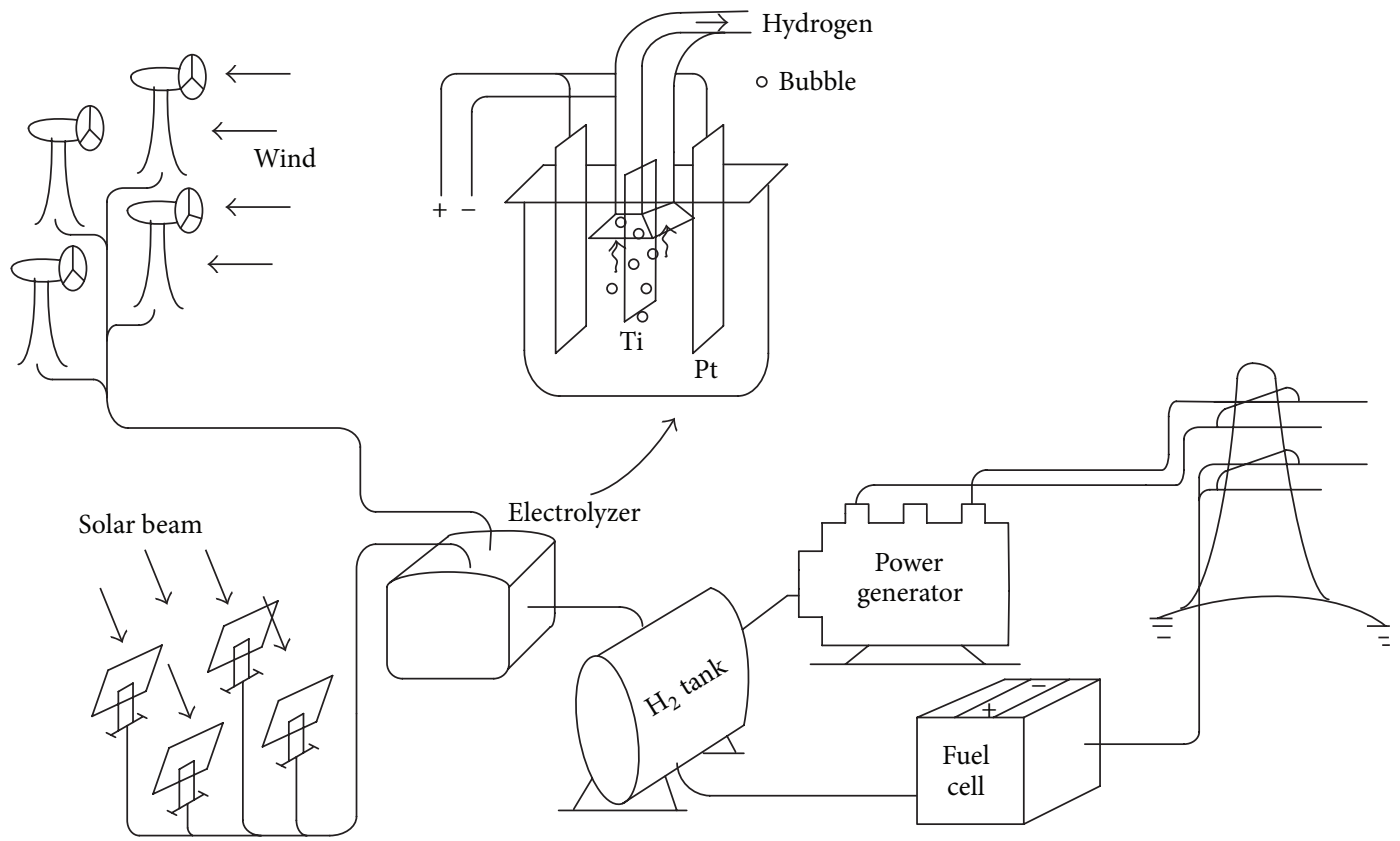

FIGURE 1: Schematic diagram showing hydrogen gas produced and stored from renewable power.

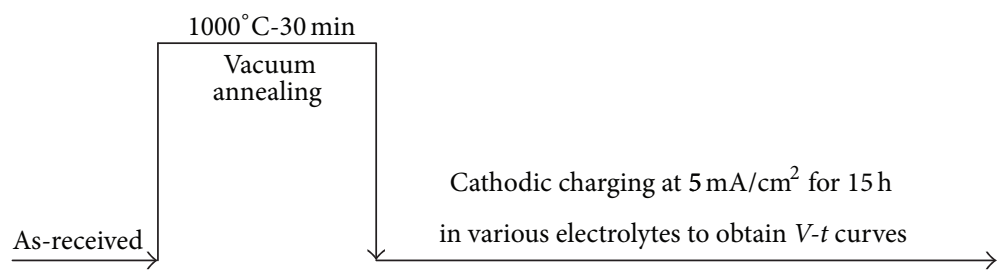

(a)

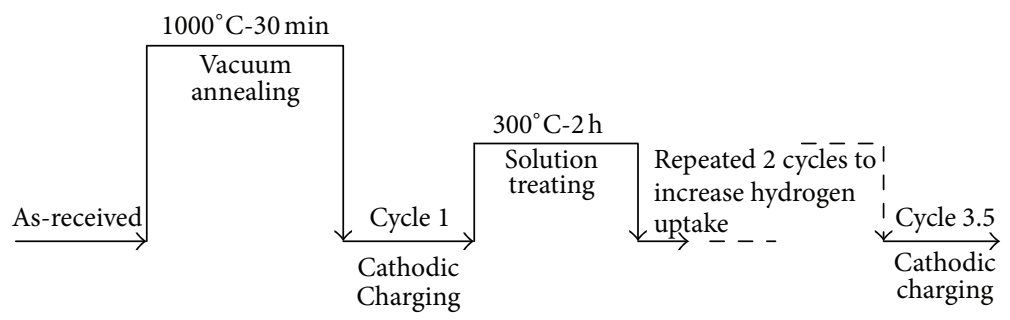

(b)

FIGURE 2: Schematic diagrams for (a) the process to monitor the variation of cathode potential versus time and (b) the cyclic hydrogenationsolution heat treating process to increase the hydrogen uptake of cathodes.

the received sheets to be $40 \times 14 \times 1 \mathrm{~mm}^{3}$ for $\mathrm{CP}$-Ti, while they are $62 \times 16 \times 0.4 \mathrm{~mm}^{3}$ for Ti-153, vacuum annealed at $1000^{\circ} \mathrm{C}$ for 30 minutes and furnace cooled to room temperature. The vacuum annealed specimens were abraded with emery paper (up to grit 1200) and further lapped to minimize the interference of surface oxides on hydrogenation. Table 1 listed the chemical compositions of the as-received sheets. Table 2 summarized the surface roughness measured by employing a profile measuring system (Dektek 150, Veeco).

The processing parameters listed in Table 3 were designed to reveal the effect of the additives on the electrochemical behavior of cathode and grouped into three sets according to the additives in the electrolyte as follows: (1) no additive in $1 \mathrm{~N} \mathrm{H}_{2} \mathrm{SO}_{4(\mathrm{aq})}$, denoted by $\mathrm{S}$, (2) $1 \mathrm{~N} \mathrm{H}_{2} \mathrm{SO}_{4(\mathrm{aq})}$ by adding $0.005 \mathrm{M}$ arsenic trioxide $\left(\mathrm{As}_{2} \mathrm{O}_{3}\right)$, denoted by $\mathrm{A}$, (3) $1 \mathrm{~N} \mathrm{H}_{2} \mathrm{SO}_{4(\mathrm{aq})}$ by adding $0.01 \mathrm{M}$ thiourea $\left(\mathrm{SC}\left(\mathrm{NH}_{2}\right)_{2}\right)$, denoted by $\mathrm{T}$, respectively. Electrolytic hydrogenation was performed at $5 \mathrm{~mA} / \mathrm{cm}^{2}$ for $15 \mathrm{~h}$ in various electrolytes, respectively. The preheat treatment was schematically shown in Figure 2(a). Figure 2(b) showed the schematic diagram of cyclic hydrogenation-solution heat treating processes. Electrolytic hydrogenation of the cyclic process was performed 
TABLE 1: (a) Analyzed composition of the as-received CP-Ti sheet (wt.\%). (b) Analyzed composition of the as-received Ti-153 sheet (wt.\%).

(a)

\begin{tabular}{lccccc}
\hline $\mathrm{H}$ & $\mathrm{C}$ & $\mathrm{N}$ & $\mathrm{O}$ & $\mathrm{Fe}$ & $\mathrm{Ti}$ \\
\hline $68 \mathrm{ppm}$ & 0.10 & 0.01 & 0.12 & 0.20 & Balanced \\
\hline
\end{tabular}

(b)

\begin{tabular}{lccccccccc}
\hline $\mathrm{H}$ & $\mathrm{C}$ & $\mathrm{N}$ & $\mathrm{O}$ & $\mathrm{Fe}$ & $\mathrm{Al}$ & $\mathrm{Cr}$ & $\mathrm{Sn}$ & $\mathrm{V}$ & $\mathrm{Ti}$ \\
\hline 0.015 & 0.05 & 0.04 & 0.11 & 0.25 & 3.1 & 3.0 & 2.8 & 14.5 & Balanced \\
\hline
\end{tabular}

TABLE 2: Surface roughness of CP-Ti and Ti-153 sheet specimens before hydrogenation.

\begin{tabular}{lccc}
\hline \multicolumn{2}{c}{ CP-Ti } & \multicolumn{2}{c}{ Ti-153 } \\
$R_{a}(\mathrm{~nm})$ & $R_{q}(\mathrm{~nm})$ & $R_{a}(\mathrm{~nm})$ & $R_{q}(\mathrm{~nm})$ \\
\hline $134.7 \pm 3.5$ & $166.3 \pm 3.8$ & $162.6 \pm 10.6$ & $171.1 \pm 15.0$ \\
\hline
\end{tabular}

$R_{a}$ : The arithmetic mean of the departure of the profile from the mean line. $R_{q}$ : The root-mean-square parameter corresponding to $R_{a}$.

TABLE 3: Process designations and the associated parameters for cathode potential monitoring.

\begin{tabular}{|c|c|}
\hline Designations & Parameters \\
\hline $\mathrm{O}$ & $\begin{array}{l}\beta \text { solution treated specimens ground by } \\
\text { emery paper to } 1000 \text { mesh }\end{array}$ \\
\hline S & $\begin{array}{l}\text { Ground specimens cathodic charged in } 1 \mathrm{~N} \\
\mathrm{H}_{2} \mathrm{SO}_{4(\mathrm{aq})} \text { at } 5 \mathrm{~A} / \mathrm{cm}^{2} \text { for } 15 \mathrm{~h}\end{array}$ \\
\hline A & $\begin{array}{l}\text { Ground specimens cathodic charged in } 1 \mathrm{~N} \\
\mathrm{H}_{2} \mathrm{SO}_{4(\mathrm{aq})}+0.005 \mathrm{M} \mathrm{As}_{2} \mathrm{O}_{3} \text { at } 5 \mathrm{~A} / \mathrm{cm}^{2} \text { for } \\
15 \mathrm{~h}\end{array}$ \\
\hline $\mathrm{T}$ & $\begin{array}{l}\text { Ground specimens cathodic charged in } 1 \mathrm{~N} \\
\mathrm{H}_{2} \mathrm{SO}_{4(\mathrm{aq})}+0.01 \mathrm{M} \text { thiourea at } 5 \mathrm{~A} / \mathrm{cm}^{2} \text { for } \\
15 \mathrm{~h}\end{array}$ \\
\hline
\end{tabular}

in $1 \mathrm{~N} \mathrm{H}_{2} \mathrm{SO}_{4(\mathrm{aq})}$ containing $\mathrm{As}_{2} \mathrm{O}_{3}(0.1 \mathrm{~g} / \mathrm{L})$ at $50 \mathrm{~mA} / \mathrm{cm}^{2}$ for $30 \mathrm{~h}$ on CP-Ti specimens while for $10 \mathrm{~h}$ on Ti-153 ones preventing the hydride layer from spallation or the specimen from cracking. The subsequent solution treatments were accomplished in a muffle furnace at $300^{\circ} \mathrm{C}$ for $2 \mathrm{~h}$. Table 4 listed designations and processing parameters of the cyclic hydrogenation-solution processes.

The effects of processing parameters on the hydrogenation behavior were evaluated qualitatively by utilizing X-ray diffractometry (XRD: X'Pert PRO MPD, PANalytical, the Netherlands, $45 \mathrm{kV}-40 \mathrm{~mA}$ ) and $V$ - $t$ curve monitoring. The quantitative cathodic behavior and hydrogen uptake of CP$\mathrm{Ti}$ and Ti-153 specimens were analyzed by the employment of glow discharge optical spectrometry (GDOS: LECO GDS750).

\section{Results and Discussion}

Large amounts of hydrogen absorption would lead to the shift and broadening of $\alpha$ peaks and presence of $\delta$ peaks in the XRD patterns of CP-Ti specimens. Patterns $S$, T, and A in

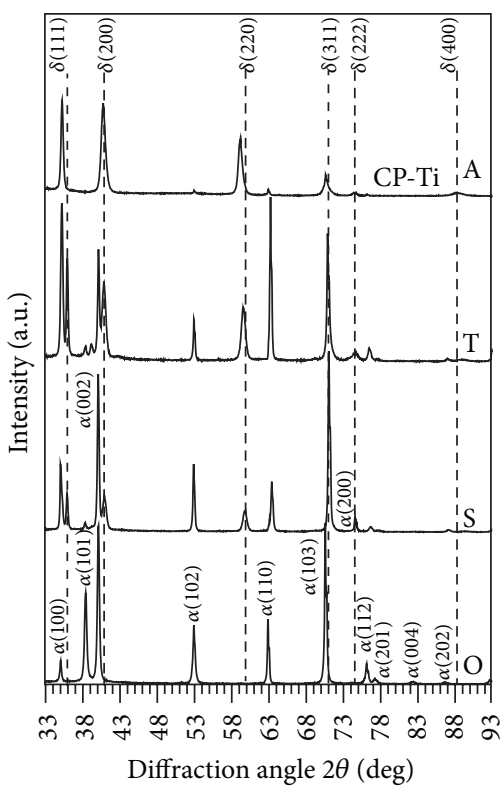

(a)

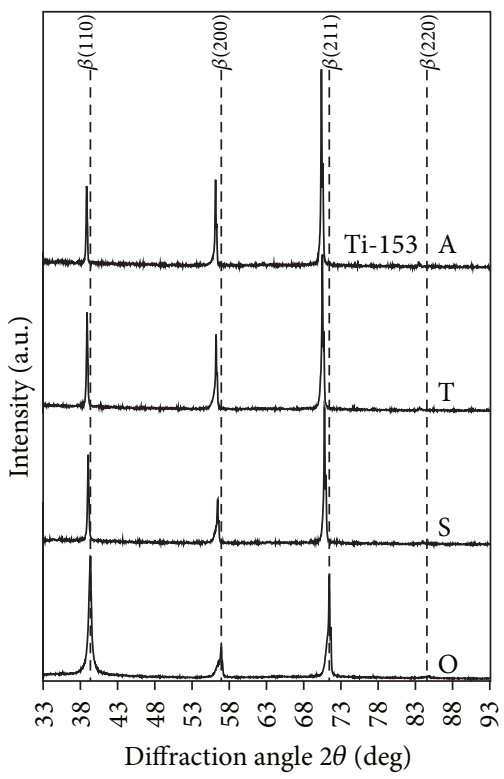

(b)

FIGURE 3: XRD patterns for as-received specimens and those after cathodic charged in various electrolytes: (a) CP-Ti and (b) Ti-153.

Figure 3(a) exhibited $\delta$ peaks in contrast to pattern $\mathrm{O}[17-$ 20]. The lower diffraction angle of the $\delta$ (220) peak implies higher hydrogen content for the certain adopted process. Both values of the relative peak height ratio, $\delta(200) / \alpha(101)$, and the angular position of $\delta$ (220) peak for $\mathrm{S}, \mathrm{T}$, and $\mathrm{A}$ processes qualitatively corroborated stronger hydrogenation promotive effect of arsenic trioxide than that of thiourea on CP-Ti specimens. The cathodic potentials in Figure 4(a) were $\mathrm{A}, \mathrm{T}$, and $\mathrm{S}$ in an ascending order, which means that both arsenic trioxide and thiourea are hydrogenation promoters during cathodic charging [19-22]. Figure 3(b) showed the XRD patterns for Ti-153 specimens after S, T and 
TABLE 4: Designations and the associated parameters of the cyclic hydrogenation-solution treatments.

\begin{tabular}{|c|c|}
\hline $\begin{array}{l}\text { Process } \\
\text { designations }\end{array}$ & The associated processing parameters \\
\hline $\mathrm{H}$ & $\begin{array}{l}\text { Specimens hydrogenated at } 5 \mathrm{~mA} / \mathrm{cm}^{2} \text { for } 30 \mathrm{~h} \text { in } 1 \mathrm{~N} \mathrm{H}_{2} \mathrm{SO}_{4(\mathrm{aq})} \text { by adding } 0.1 \mathrm{~g} / \mathrm{L} \mathrm{As}_{2} \mathrm{O}_{3} \text {, followed by a solution heat } \\
\text { treatment at } 300^{\circ} \mathrm{C} \text { for } 2 \mathrm{~h} \text { and then air cooled to room temperature }\end{array}$ \\
\hline $\mathrm{H} 3$ & $\begin{array}{l}\text { Specimens processed three cycles according to } \mathrm{H} \text { and then followed by a further hydrogenation at } 5 \mathrm{~mA} / \mathrm{cm}^{2} \text { for } 30 \mathrm{~h} \text { in } \\
1 \mathrm{~N} \mathrm{H}_{2} \mathrm{SO}_{4(\mathrm{aq})} \text { by adding } 0.1 \mathrm{~g} / \mathrm{L} \mathrm{As}_{2} \mathrm{O}_{3}\end{array}$ \\
\hline I & $\begin{array}{l}\text { Specimens hydrogenated at } 5 \mathrm{~mA} / \mathrm{cm}^{2} \text { for } 10 \mathrm{~h} \text { in } 1 \mathrm{~N} \mathrm{H}_{2} \mathrm{SO}_{4(\mathrm{aq})} \text { by adding } 0.1 \mathrm{~g} / \mathrm{L} \mathrm{As}_{2} \mathrm{O}_{3} \text {, followed by a solution heat } \\
\text { treatment at } 300^{\circ} \mathrm{C} \text { for } 2 \mathrm{~h} \text { and then air cooled to room temperature }\end{array}$ \\
\hline I3 & $\begin{array}{l}\text { Specimens processed three cycles according to } \mathrm{I} \text { and then followed by a further hydrogenation at } 5 \mathrm{~mA} / \mathrm{cm}^{2} \text { for } 10 \mathrm{~h} \text { in } \\
1 \mathrm{~N} \mathrm{H}_{2} \mathrm{SO}_{4(\mathrm{aq})} \text { by adding } 0.1 \mathrm{~g} / \mathrm{L} \mathrm{As}_{2} \mathrm{O}_{3}\end{array}$ \\
\hline $\mathrm{OCH} 3$ & $\beta$ solution treated CP-Ti specimens ground by emery paper to 1000 mesh and then treated with $\mathrm{H} 3$ process \\
\hline OBI3 & $\beta$ solution treated Ti-153 specimens ground by emery paper to 1000 mesh and then treated with $\mathrm{I} 3$ process \\
\hline
\end{tabular}

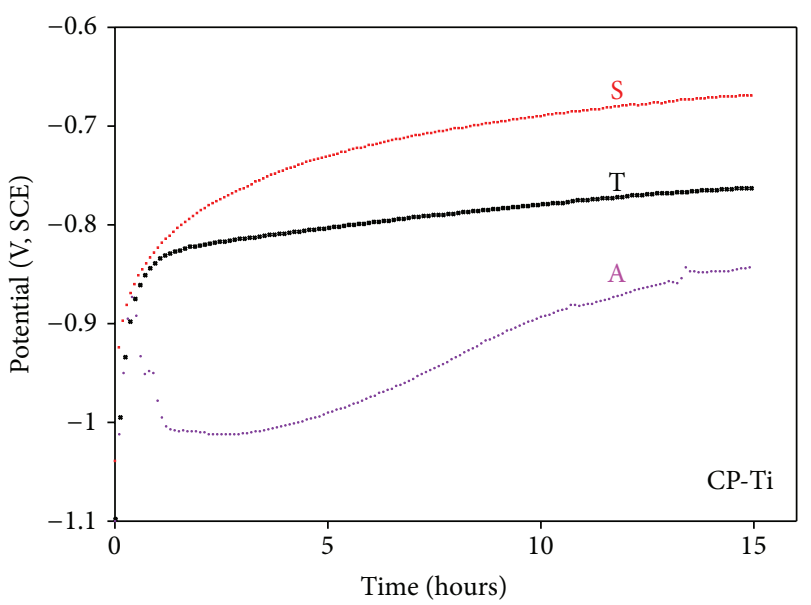

(a)

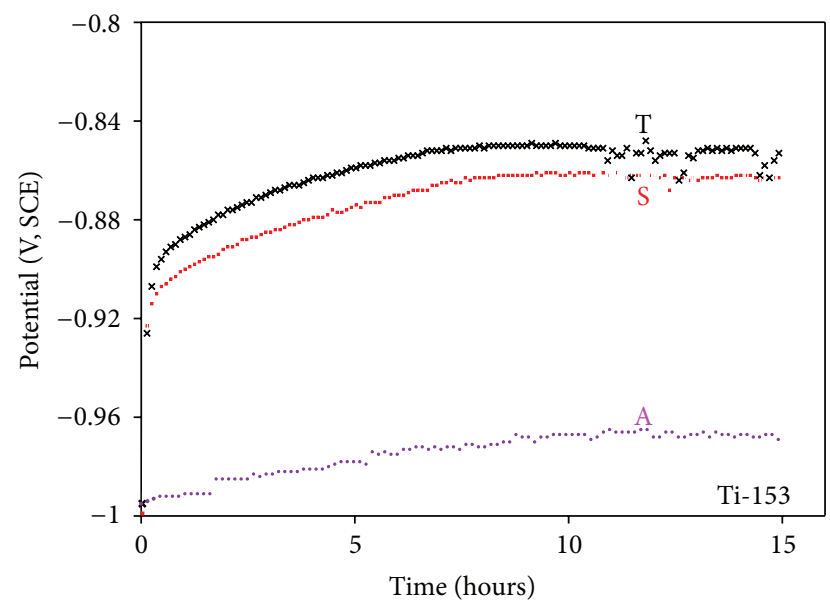

(b)

Figure 4: $V$ - $t$ curves for (a) CP-Ti and (b) Ti-153 specimens cathodic charged in various electrolytes.

A treatments. Electrolytic hydrogenation under the applied conditions did not lead to precipitation of hydrides but to a shift of $\beta$ peaks. The larger angle the peak shifted, the larger amount of hydrogen the specimen absorbed [23]. The angular shifts of all four $\beta$ peaks in Figure 3(b) were $A, S$ and $\mathrm{T}$ in a descending order, while the cathodic potentials

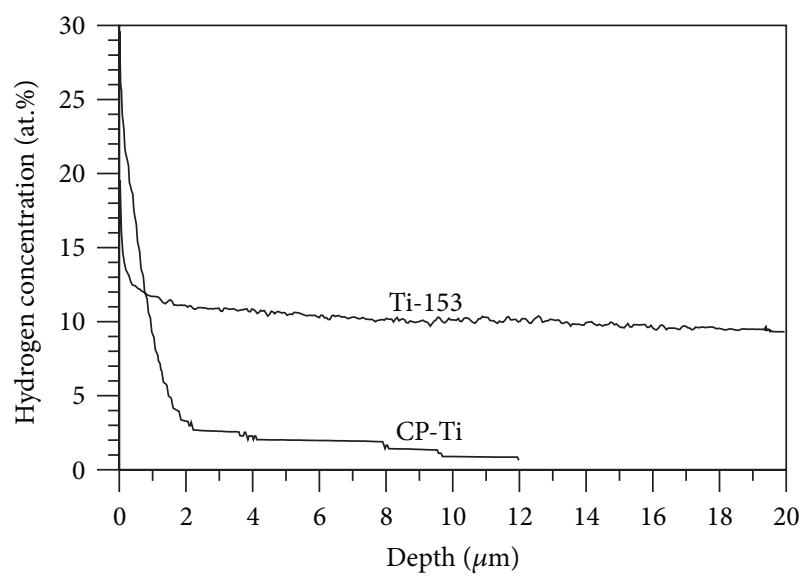

FIgure 5: Hydrogen depth profiles of CP-Ti and Ti-153 specimens after cyclic hydrogenation and subsequent solution heat treatment.

in Figure 4(b) were A, S, and T in an ascending order. The higher cathodic potentials and lower hydrogen absorption for process $\mathrm{T}$ performed on $\mathrm{Ti}-153$ specimens mean that thiourea in $1 \mathrm{~N} \mathrm{H}_{2} \mathrm{SO}_{4(\mathrm{aq})}$ is a hydrogenation inhibitor for Ti-153 specimens under the conditions. Since arsenic trioxide was a hydrogen promoter for both CP-Ti and Ti-153 specimens during cathodic charging, it was chosen as the hydriding catalyst added in the following cyclic hydrogenation-solution heat treating processes to enhance hydrogen uptake.

Figure 5 showed the hydrogen depth profiles of $\mathrm{OCH} 3$ and OBI3 specimens after cyclic hydrogenation-solution treatment. Quantitative hydrogen distribution curves were obtained by employing GDOS. The analyses of hydrogen uptake were accomplished by simply summing the specific hydrogen content (SHC) from the specimen surface to the maximum hydrogen diffusion depth (MHD) listed in Table 5. The SHC can be derived from total hydrogen content (THC) as shown in the following formula $[24,25]$ :

THC from layer $o$ to layer $f$

$$
\begin{aligned}
& =\mathrm{THC}_{d o-d f}=\int_{d o}^{d f} C_{x} d M=\int_{d o}^{d f} C_{x}\left(\rho_{x} d V\right) \\
& =\int_{d o}^{d f} C_{x}\left(\rho_{x} A d x\right),
\end{aligned}
$$


TABLE 5: Values of MHD $(\mu \mathrm{m})$ and SHC for OCH3 and OBI3 processes.

\begin{tabular}{lccc}
\hline \multicolumn{4}{c}{$\begin{array}{c}\text { SHC }\left(\mathrm{mg} / \mathrm{m}^{2}\right) \\
\text { of various specimens within various intervals below } \\
\text { the specimen's surface }(\mu \mathrm{m})\end{array}$} \\
& $\mathrm{OCH} 3$ & $\mathrm{OBI3}$ \\
\hline $\mathrm{MHD}$ & 12 & $\mathrm{MHD}$ & 90 \\
$\mathrm{SHC}_{0-1}$ & 18.1 & $\mathrm{SHC}_{0-1}$ & 21.4 \\
$\mathrm{SHC}_{1-2}$ & 4.9 & $\mathrm{SHC}_{1-2}$ & 18 \\
$\mathrm{SHC}_{2-3}$ & 3.3 & $\mathrm{SHC}_{2-3}$ & 18.8 \\
$\mathrm{SHC}_{3-4}$ & 3.1 & $\mathrm{SHC}_{3-4}$ & 17.8 \\
$\mathrm{SHC}_{4-5}$ & 2.8 & $\mathrm{SHC}_{4-5}$ & 17.7 \\
$\mathrm{SHC}_{5-6}$ & 2.4 & $\mathrm{SHC}_{5-6}$ & 16.9 \\
$\mathrm{SHC}_{6-7}$ & 1.8 & $\mathrm{SHC}_{6-7}$ & 17.9 \\
$\mathrm{SHC}_{7-\mathrm{MHD}}$ & 1.8 & $\mathrm{SHC}_{7-8}$ & 16.9 \\
& & $\mathrm{SHC}_{8-9}$ & 17.0 \\
& & $\mathrm{SHC}_{9-10}$ & 18.0 \\
$\mathrm{SHC}_{0-\mathrm{MHD}}$ & 38.2 & $\mathrm{SHC}_{0-\mathrm{MHD}}$ & 860 \\
\hline
\end{tabular}

where $d o$ and $d f$ are the depth of layer $o$ and layer $f$, respectively, $C_{x}$ is the local hydrogen content in weight or atomic percentage, $d M$ is the differential quantity of local mass, $\rho_{x}$ is the local density, $d V$ is the differential quantity of local volume, $A$ is the cross-sectional area concerned, and $d x$ is the differential quantity along the depth. Since $A$ is constant, the formula in (1) can be further simplified as:

$$
\mathrm{THC}_{d o-d f}=A \int_{d o}^{d f} C_{x} \rho_{x} d x=\mathrm{SHC}_{d o-d f} \times A
$$

Since the area $A$ in (2) is a determined value, the comparison of SHC is equivalent to that of THC. SHC values can outcome automatically after GDOS analyses. The SHC values were adopted to list in Table 5 to see the hydrogen mass payload between CP-Ti and Ti-153 cathodes. The $\mathrm{SHC}_{0-\mathrm{MHD}}$ for $\mathrm{OCH} 3$ and $\mathrm{OBI} 3$ are $38.2 \mathrm{mg} / \mathrm{m}^{2}$ and $860 \mathrm{mg} / \mathrm{m}^{2}$, respectively. The charging period for $\mathrm{OCH} 3$ was three times longer than that for OBI3. The ratio of hydrogen absorption for OBI3 to that for $\mathrm{OCH} 3$ can be easily estimated as $(860 \times 3) \div 38.2=67.5$. The specific weight of Ti-153 is about 4.42 while that of CP-Ti is about 4.51 . Higher hydrogen uptake ability combines lower density. Ti-153 shows obvious superiority to CP-Ti in hydrogen mass payload.

\section{Conclusions}

Both arsenic trioxide and thiourea are hydrogenation promoters for CP-Ti, while thiourea shows inhibitive effect on Ti-153 under the applied conditions. Arsenic trioxide is a hydrogenation promoter for both $\mathrm{Ti}-153$ and $\mathrm{CP}-\mathrm{Ti}$ in this study. Ti-153 is superior to CP-Ti in serving as the cathode for photovoltaic hydrogen production. The hydrogen mass payload for Ti-153 is estimated to be more than 68 times in contrast to that for CP-Ti.

\section{Acknowledgments}

The authors are grateful for the financial support of this research by the Tatung University and the National Science Council under Grant nos. B101-T08-012 and NSC 101-2622E-036-002-CC3, respectively.

\section{References}

[1] S. Iu. Bortnikov, N. S. Lidorenko, G. F. Muchnik, S. V. Riabikov, and D. S. Strebkov, Solar-Energy Perspectives, International Energy Agency, 2011.

[2] P. Gipe, "The wind industry's experience with aesthetic criticism," Leonardo, vol. 26, no. 3, pp. 243-248, 1993.

[3] Association for Industrial Archaeology, Industrial Archaeology Review, vol. 10-11, Oxford University Press, 1987.

[4] D. Kerr, "Marine energy," Philosophical Transactions of the Royal Society A, vol. 365, no. 1853, pp. 971-992, 2007.

[5] F. Qiang, "Radiation (solar)," in Encyclopedia of Atmospheric Sciences, J. R. Holton, Ed., pp. 1859-1863, Academic Press, 2003.

[6] B. Sorensen, Renewable Energy: Physics, Engineering, Environmental Impacts, Economics \& Planning, Elsevier Science, 2010.

[7] B. M. Diaconu, "Energy analysis of a solar-assisted ejector cycle air conditioning system with low temperature thermal energy storage," Renewable Energy, vol. 37, no. 1, pp. 266-276, 2012.

[8] Y. Tian and C. Y. Zhao, "A review of solar collectors and thermal energy storage in solar thermal applications," Applied Energy, vol. 104, pp. 538-553, 2013.

[9] L. Li, L. Duan, Y. Xu, M. Gorlov, A. Hagfeldt, and L. Sun, "A photoelectrochemical device for visible light driven water splitting by a molecular ruthenium catalyst assembled on dyesensitized nanostructured $\mathrm{TiO}_{2}$," Chemical Communications, vol. 46, no. 39, pp. 7307-7309, 2010.

[10] T. L. Gibson and N. A. Kelly, "Predicting efficiency of solar powered hydrogen generation using photovoltaic-electrolysis devices," International Journal of Hydrogen Energy, vol. 35, no. 3, pp. 900-911, 2010.

[11] J. M. Pearce, "Photovoltaics-a path to sustainable futures," Futures, vol. 34, no. 7, pp. 663-674, 2002.

[12] J. L. Bernal-Agustín and R. Dufo-López, "Hourly energy management for grid-connected wind-hydrogen systems," International Journal of Hydrogen Energy, vol. 33, no. 22, pp. 6401-6413, 2008.

[13] R. B. Gupta, Hydrogen Fuel: Production, Transport, and Storage, Taylor \& Francis, 2009.

[14] F. Rigas and P. Amyotte, Hydrogen Safety, CRC Press, 2012.

[15] J. O. Jensen, A. P. Vestbø, Q. Li, and N. J. Bjerrum, “The energy efficiency of onboard hydrogen storage," Journal of Alloys and Compounds, vol. 446-447, pp. 723-728, 2007.

[16] J. F. Newman and L. L. Shreir, "Role of hydrides in hydrogen entry into steel from solutions containing promoters," Corrosion Science, vol. 9, no. 8, pp. 631-641, 1969.

[17] T.-I. Wu, C.-T. Liu, and J.-K. Wu, "Use of thiourea to inhibit the incorporation of hydrogen in Ti and Ti-6Al-4V alloy," Materials Letters, vol. 30, no. 5-6, pp. 377-383, 1997.

[18] T.-I. Wu and J.-K. Wu, "Effects of thiourea and its derivatives on the electrolytic hydrogenation behavior of Ti-6Al-4V alloy," Materials Letters, vol. 53, no. 3, pp. 193-199, 2002.

[19] T.-I. Wu and J.-K. Wu, "Effects of electrolytic hydrogenating parameters on structure and composition of surface hydrides 
of CP-Ti and Ti-6Al-4V alloy," Materials Chemistry and Physics, vol. 74, no. 1, pp. 5-12, 2002.

[20] T.-I. Wu and J.-K. Wu, "The effects of chemical additives on the hydrogen uptake behavior of Ti-6Al-4V alloy," Materials Chemistry and Physics, vol. 80, no. 1, pp. 150-156, 2003.

[21] H. H. Uhlig and R. W. Revie, Corrosion and Corrosion Control: An Introduction to Corrosion Science and Engineering, John Wiley \& Sons, 1985.

[22] P. Marcus, Corrosion Mechanisms in Theory and Practice, CRC Press, 2011.

[23] B.-S. Lee, Effects of cyclic hydrogenation and subsequent solution treatment on the mechanical properties of Ti-153 alloy [M.S. thesis], Department of Materials Engineering, Tatung University, Taipei, Taiwan, 2012.

[24] J.-C. Wu and T.-I. Wu, "Influences of the cyclic electrolytic hydrogenation and subsequent solution treatment on the hydrogen absorption and evolution of $\beta$-solution treated Ti6Al-4V alloy," International Journal of Hydrogen Energy, vol. 33, no. 20, pp. 5651-5660, 2008.

[25] T.-I. Wu and J.-C. Wu, "Effects of cathodic charging and subsequent solution treating parameters on the hydrogen redistribution and surface hardening of Ti-6Al-4V alloy," Journal of Alloys and Compounds, vol. 466, no. 1-2, pp. 153-159, 2008. 

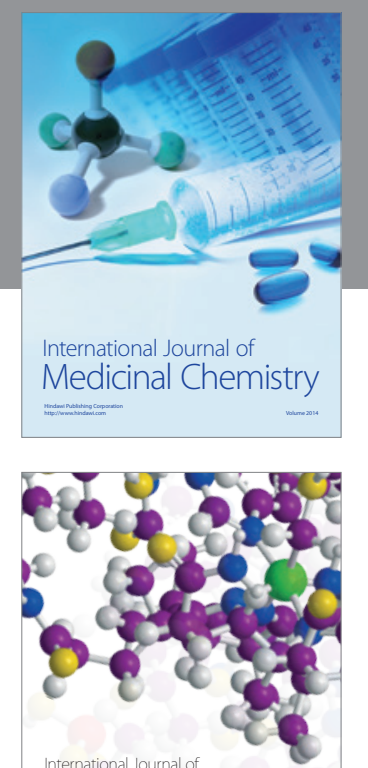

\section{Carbohydrate} Chemistry

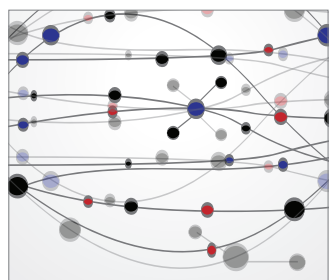

The Scientific World Journal
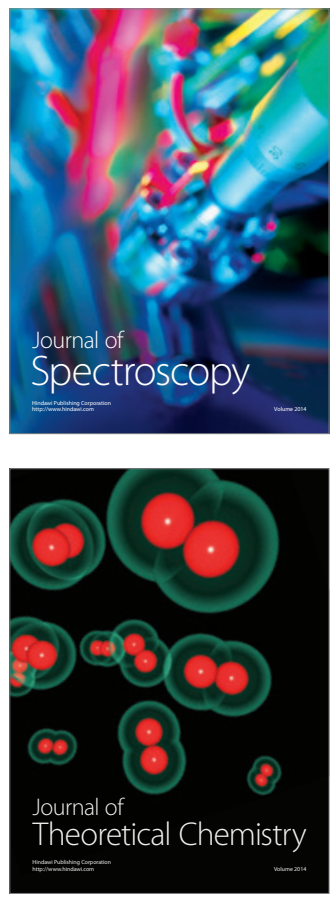
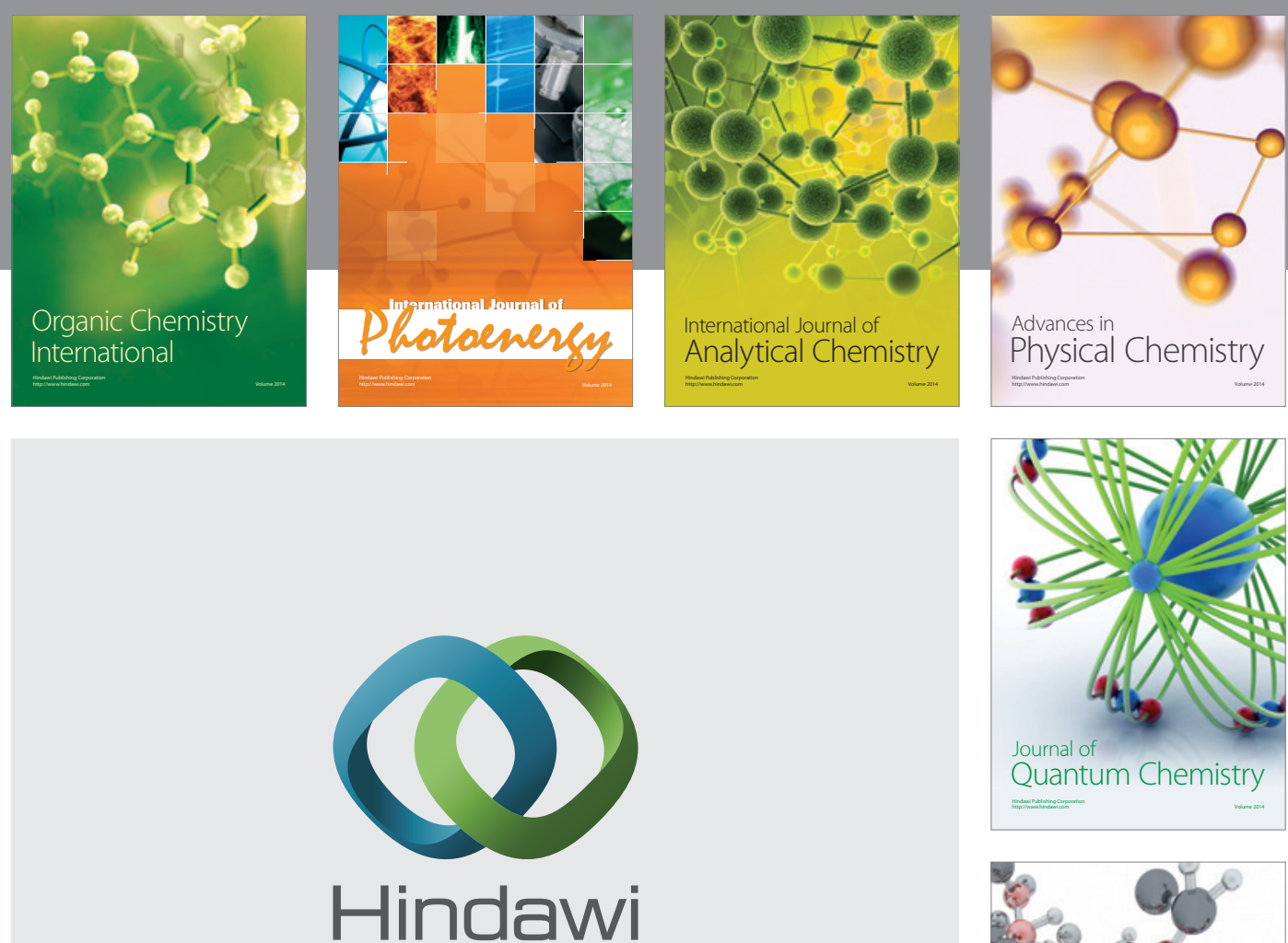

Submit your manuscripts at

http://www.hindawi.com

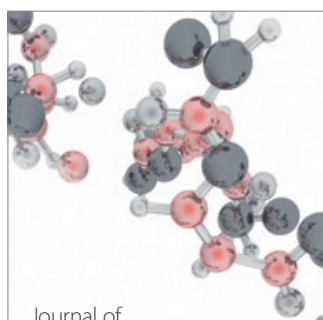

Analytical Methods

in Chemistry

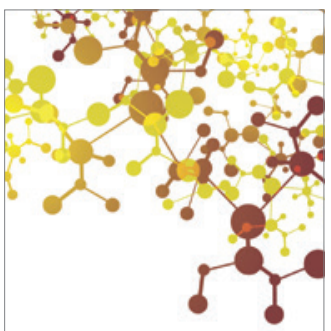

Journal of

Applied Chemistry

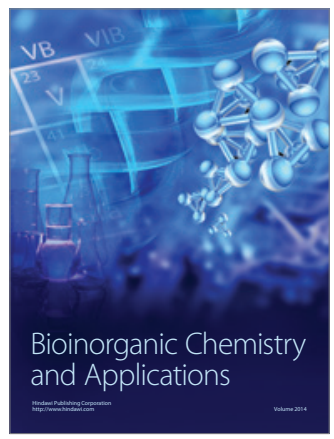

Inorganic Chemistry
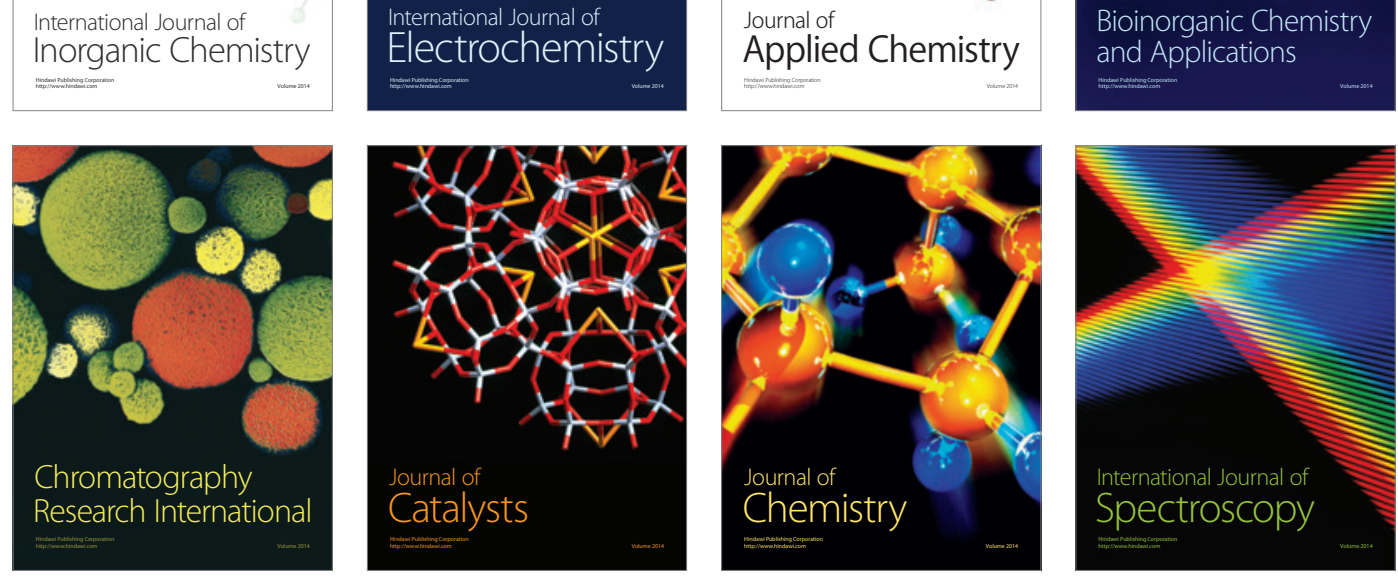